\title{
Load Balance Design of Google Cloud Compute Engine VPS with Round Robin Method in PT. Lintas Data Indonesia
}

\author{
Desmulyati ${ }^{1 \text { st }}$ \\ STMIK Nusa Mandiri \\ Jakarta, Indonesia \\ desmulyati.dmy@nusamandiri.ac.id
}

\author{
Muhammad Rizki Perdana Putra ${ }^{\text {2nd }}$ \\ STMIK Nusa Mandiri \\ Jakarta, Indonesia \\ muhrizki16@outlook.co.id
}

\begin{abstract}
One of the providers of cloud computing services is the Google Cloud Platform developed by Google LLC. PT Lintas Data Indonesia as a vendor and distributor of technology devices is in dire need of a web server for the publicity of its products. At present, PT Lintas Data Indonesia's web server system still uses the services of hostgator hosting providers with packages with limited resources and also cannot implement system load balances and fail over on the current server system, in terms of latency access speed when pinging web servers in HostGator is quite high up to $200 \mathrm{Ms}$. To improve the performance of a web server so that a load balance and fail over system can be implemented, migrating to the Google Cloud Platform environment is a solution that is expected to be able to handle existing problems. The advantages of Google Cloud Platform are servers that are rented for web servers in the form of Virtual Private Servers (VPS) so that they are easy to maintain and if you want to upgrade services. The addition of three web servers in the cluster with HAProxy server makes PT Lintas Data Indonesia's web server service more reliable in handling requests, load balances with round robin methods and fail over web servers and with HAProxy it is proven that it can increase up to $150 \%$ in handling latency issues previously it was around $30 \mathrm{Ms}$.
\end{abstract}

Keywords - Cloud, Compute Engine, Round Robin, Load Balance

\section{INTRODUCTION}

Cloud computing is one of the most efficient digital solutions in all aspects. One provider of cloud computing services such as Google Cloud promises to be the latest and fastest cloud computing solution today, according to (Challita et al. 2018)"Among the cloud APIs, Google Cloud Platform (GCP) is today one of the most important and growing in the cloud market. It provides developers several products to build a range of programs from simple websites to complex worldwide distributed applications." The existence of a cloud computing solution by Google Cloud is considered to solve the problem of providing a lightweight website to programming complex. A big problem that often occurs in cloud computing is Load Balancing, the number of Virtual Machines (VMs) that use cloud computing is very difficult to allocate in the cloud manually according to user needs, therefore the need for Load Balancing techniques. According to (Singh and Kaur 2018) "With load balancing of servers, users no longer experience network downtime, slow information recovery, or aborted connections." So, with the existence of Load Balancing, it is expected to make VMs more stable and escalated properly.

PT. Lintas Data Indonesia is a company engaged in the Audio, Video and Visual sectors with 11 employees. The company sells a variety of equipment to support High Definition (HD) Video Confrencing and Audio Systems that work with several vendors such as Kramer Electronic, ClearOne, LifeSize, Polycom, and others. The image of companies in the digital world today has become an absolute thing in assessing the integrity of a company. Co-location is one of the digital solutions currently used by PT. Lintas Data Indonesia to make web servers and storage servers publicly accessible. Public access to the web server of PT. Indonesian 
Data Cross is something that cannot be predicted when a user accesses it simultaneously, the excess load on the server can make the Quality of Service (QoS) decrease on the server itself and can even make down existing web servers. Co-location is very expensive compared to renting a hosting server, but most hosting servers are shared servers that make it have limited resources and are difficult to upgrade unless we migrate our servers to rent new hosting with greater resources.

Google Cloud is one of the cheap solutions for building cloud access that is easily accessible and easy to develop, with the cloud infrastructure the role of Load Balancing is easy to implement and this is considered to be able to balance the load on VMs and can be a Fail Over solution when one VM turns down or overloaded. According to the research results of (Rosalia, Munadi, and Mayasari 2016) "Load balancing system capabilities with three virtual servers in serving requests are far better than single virtual servers, because servers work together and the load is not centered on one server so it does not burden the server." Load Balance with the Round Robin method using the rated HAProxy application can stabilize VMs loads and effectively do a Fail Over when a failure occurs on VMs that is applied to Google Cloud.

\section{LITERATURE REVIEW}

The computer network is not something new this time. Almost every company, agency and organization has a computer network to facilitate the flow of information within the company. The internet that is becoming popular now is a giant computer network that is a computer network that is connected and interacting.

\section{A. Network Topology}

According to (Patwiyanto., Wahyuni, S., Prasetyo 2018) argues that "Network topology is a form of design used to build a computer network".

\section{Bus Topology}

According to (Patwiyanto., Wahyuni, S., Prasetyo 2018) mentions that on a network bus topology, each server and workstation are connected to a cable called a bus.

\section{Ring Topology}

(Patwiyanto., Wahyuni, S., Prasetyo 2018) says that in the type of ring topology network all networks connected from one computer to another go around forming a loop.

\section{Star Topology}

(Patwiyanto., Wahyuni, S., Prasetyo 2018) states that on this type of network each workstation is connected to a server using a concentrator.

\section{B. Cloud Computing}

Cloud Computing according to (Mengistu et al. 2017) states "... Cloud Computing is primarily based on proprietary data centers, where hundreds of thousands of dedicated servers are setup to host the cloud services." Meanwhile, according to (Lumena, Anton, and Nainggolan 2016) says that "Cloud computing technology is the latest technology in the development of the world of information technology (IT). The use of this technology will have a significant effect on the industrial world, especially in terms of operational cost savings. "Cloud computing technology has a large number of service providers, one of which is the Google Cloud Platform.

\section{Google Cloud Platform}

According to (Challita et al. 2018) "Among the cloud APIs, Google Cloud Platform (GCP) is today one of the most important and growing in the cloud market. It provides developers several products to build a range of programs from simple websites to complex world- wide distributed applications." Google Cloud Platform or GCP is a public cloud computing service from Google LLC which consists of various services. This platform from Google provides a variety of hosting services ranging from computing, storage and application development that runs on Google hardware. The Google Cloud Platform Service can be accessed by software developers, cloud administrators and other IT professionals using the public internet or through dedicated network connections.

\section{HAProxy}

According to (Rosalia, Munadi, and Mayasari 2016) HAProxy is an open source product that provides solutions to create system load balancing and failover from TCP and HTTP based applications. This software is very suitable for websites that have high daily traffic while it requires persistence and strength from processing at layer 7 . HAProxy is installed on the front-end server. The end-servers are generally servers that have a static IP registered with DNS. 


\section{RESUlT AND DISCUSSION}

For the network topology the author will not change the network topology that already exists in PT Lintas Data Indonesia because the topology currently in use is very good and runs as expected. The proposed network that the authors propose only applies the Google Cloud Platform to replace HostGator's web hosting technology as a forum for PT Lintas Data Indonesia's servers.

\subsection{Initial Network Scheme}

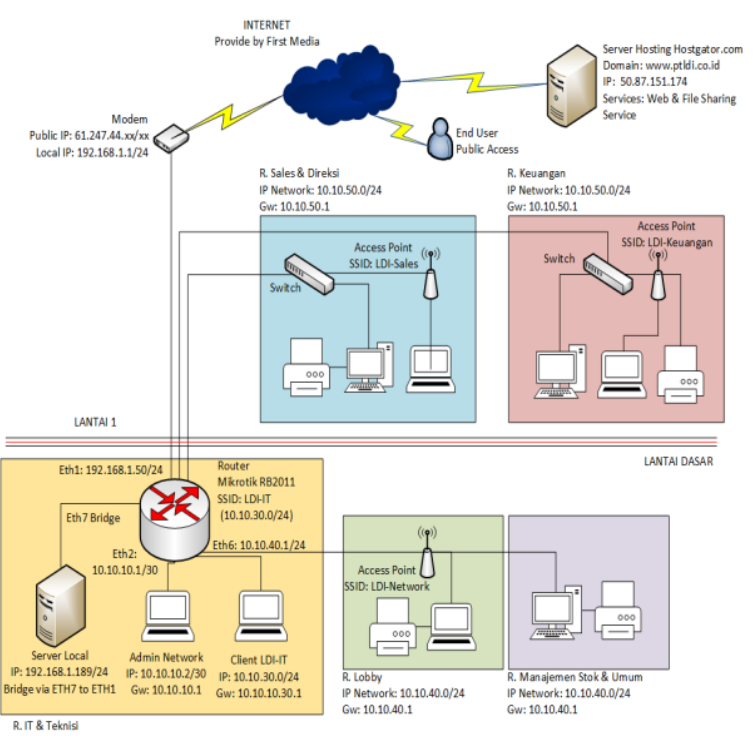

Figure 1. Initial Network Scheme

Computer networks at PT Lintas Data Indonesia consist of modems, routers, switches, servers, printers and clients. For routers using the RB-2011 Microtic Router which has 10 ports (5 Gigabit Ethernet ports and 5 Fast Ethernet ports), then there is a local server that is used for attendance and Accurate Accouting application databases. Internet Service Providers use First Media with a $50 \mathrm{Mbps}$ download and 10 Mbps upload bandwidth allocation, then the proxy router is enabled for bandwidth, proxy and gateway management. For the purposes of connecting to the client, most of them use their respective laptops that are connected to the SSID of each room, then for the client computer and the IP printer directly connected to the competition with a LAN cable that is connected to the switch of each room.

3.2. Network Scheme Using the Google Cloud Platform

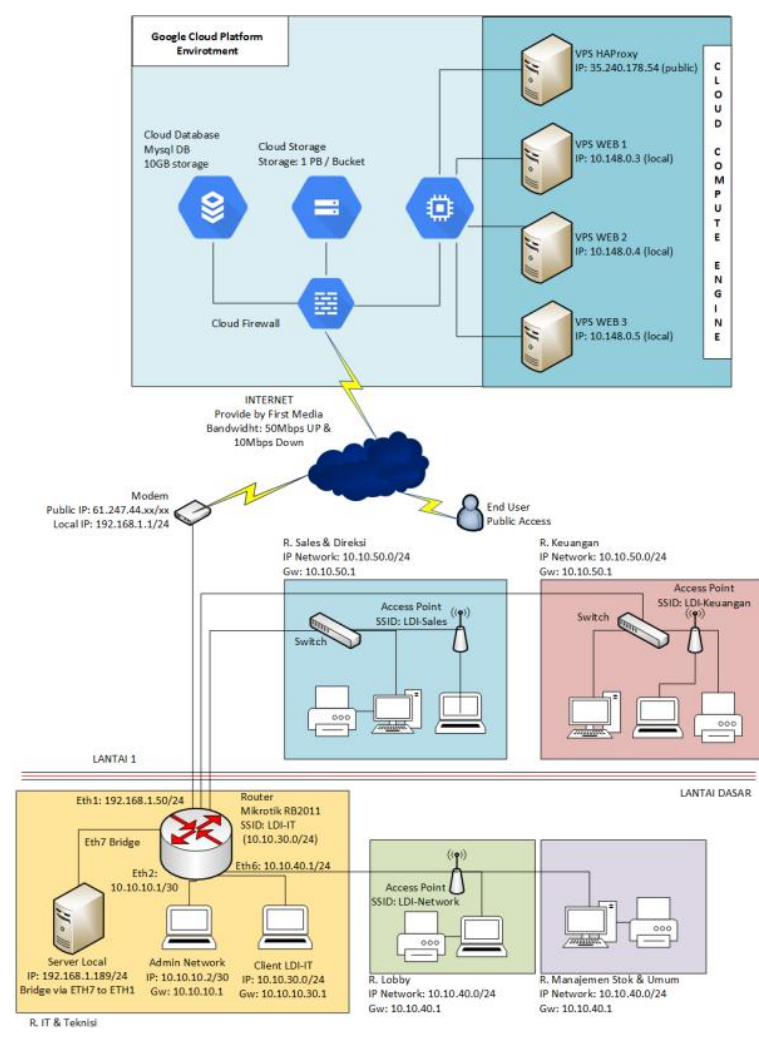

Figure 2. Network Scheme Image Using Google Cloud Platform

In the network scheme above, the addition of the scheme in the Google Cloud Platform Protection section, here the author designed a system with 4 Virtual Private Servers (Cloud) with Cloud Compute Engine, then the author also added object-based storage namely Cloud Storage Bucket with up to 1 bucket capacity PetaBytes (1 PB) or equivalent to 1,000,000 GB (GigaBytes), and finally the author added a cloud database that installed the MYSQL database system for centralized database creation and storage on the Google Cloud Platform.

In the implementation of this system, later the HAProxy server has the duty to forward packets that are requested by the client to the web server, which previously only 1 has now become 3 servers.

The addition of two web servers is intended for load balancing and fail over system if one server crashes or down, it is expected that one of the alive servers can backup requests from the client.

\subsection{Application Design}

In establishing the proposed network on PT Lintas Data Indonesia's web server located on the Google Cloud Platform there are several application systems designed so that the network can run as expected in its implementation. 


\subsubsection{HAProxy Server}

The design of the HAProxy server is intended to forward the request packet sent by the client to the web server, because there are 3 web servers in this implementation with the configuration of 2 web servers to receive requests from clients and 1 server in a backup or standby condition if a system failure occurs. web server 1 and 2 , this makes every web server has a different IP address because the pyshical web server is divided into 3 different devices. The purpose of the HAProxy server is to combine or clustering 3 existing web servers with different IP addresses to one IP address, namely the IP of the HAProxy server. In this simulation the author uses HAProxy on a server based on the Debian 9 Server operating system.

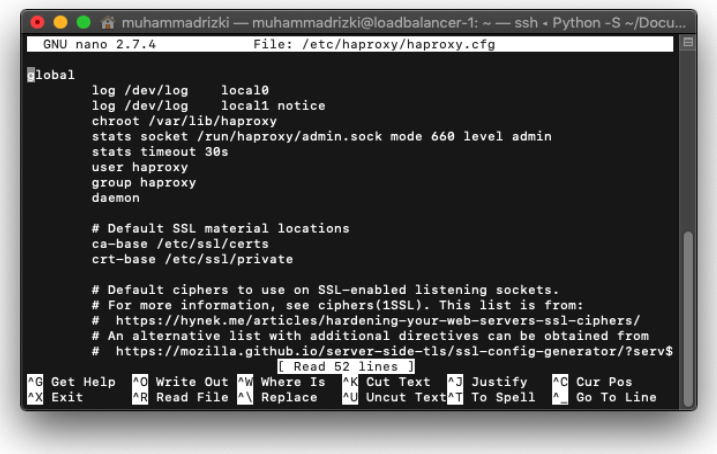

Figure 3. HAProxy Configuration

\subsubsection{Round Robin Load Balance}

Load Balance configuration with Round Robin method is implemented on the HAProxy server by registering web server nodes that will be clustered so that it can be called when the computer makes a web request that is called through the HAProxy IP server. The Round Robin Balance Load is expected to provide a stable load sharing solution to be used on web servers in PT Lintas Data Indonesia located on the Google Cloud Platform. Round Robin algorithm is assuming we have 2 interconnected web servers (web1 server and web2 server) if there is a request from the client then the first request will be served by web1 server and if there is a second request it will be served by web2 server, then will return if there is a request to be served by web1 like a circle.

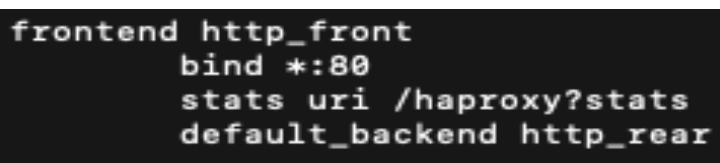

Figure 4. Configure Fowarding HAProxy to the web server cluster

In Figure 4. we can see the configuration is to check the request package that goes to the server on port 80, which is the port that is commonly used for the Hypher Text Transport Protocol (http) or web server to the backend_server labeled http_rear, which is a list of web servers available for foward and serving requests from clients. Uri Stats is to activate web pages for server monitoring purposes, by default the url is <ip_public> / haproxy? Stats, where <ip_public> is the public IP of the HAProxy server.

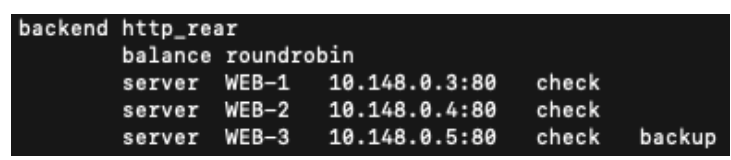

Figure 5. Configuring Load Balance Method and Clustering

In Figure 5. seen in the balance line using round robin, which means that the method used in load balance on HAProxy uses the Round Robin method. The server section shows the IP address of the web server that we cluster and is used on the HAProxy to receive requests from the client, while the addition of the check line means that the HAProxy server checks periodically about the condition of the clustered web server, then in the backup section to mark the server as a backup.

\subsection{Fail Over}

Besides that, HAProxy can be used as a load balancer, HAProxy can also be used as a provider of fail over, where if we have 2 web servers, if one of them fails the system, maintenance, or anything other than expected, the web server is not paralyzed, because there is still one web server that is still online.

\subsubsection{HAProxy Monitoring System}

HAProxy Monitoring system is a web-based application program from HAProxy, this program provides various info about the condition of the web server clustered by the HAProxy server.

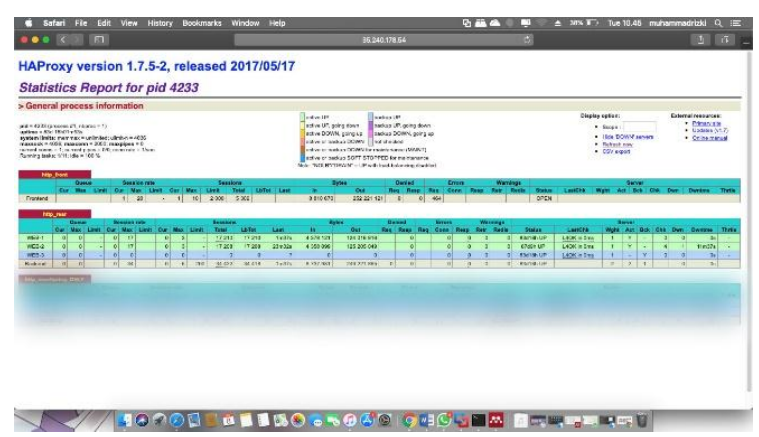

Figure.6. HAProxy Stats Page

\subsection{Network Testing}


At this stage the authors conducted a trial of computer networks that are in PT Lintas Data Indonesia. This needs to be done because this test is conducted to determine whether PT Lintas Data Indonesia's computer network has been running optimally as expected.

\subsubsection{Initial Network Testing}

Initial network testing is to see the problems that exist on the network running on PT Lintas Data Indonesia's web server. This test uses testing methods directly and real to the web server used by PT Lintas Data Indonesia, which is currently hosted by HostGator as the hosting service provider used by PT Lintas Data Indonesia.

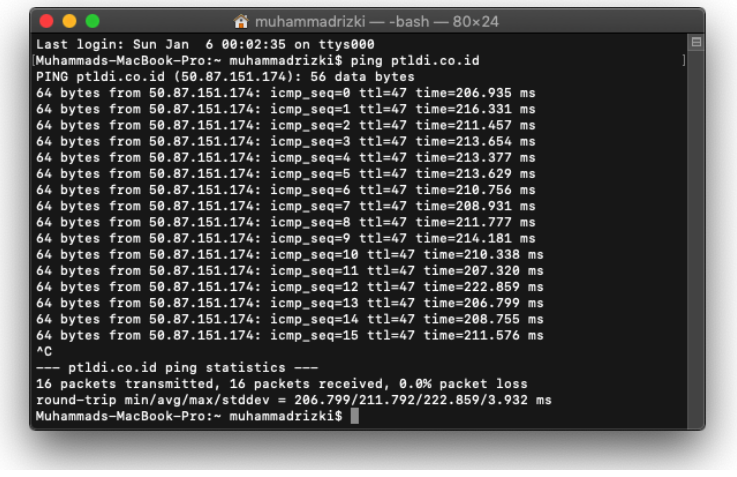

Figure 7. Test Ping to PT Lintas Data Indonesia's Web Server

From Figure 7 it can be seen that network latency that occurs when the ping process from the client publicly through the internet network of the PT Lintas Data Indonesia office has a reponse time of more than $200 \mathrm{~ms}$, this indicates that the web server hosted on HostGator has sufficient latency high and can have an effect on the speed of access of PT Lintas Data Indonesia's web server.

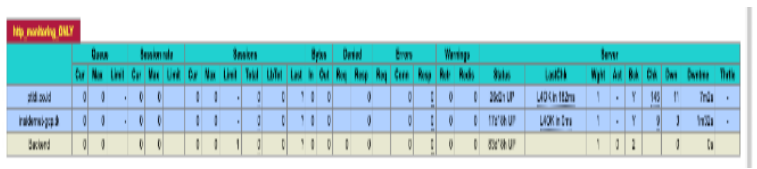

Figure 8. Results of PT Lintas Data Indonesia's Web Server Monitoring

The monitoring availability results that were carried out using the HAProxy monitoring application showed that the server status experienced a downtime of 11 times in 7 minutes 2 seconds within 26 days without notice by HostGator, this caused the PT Lintas Data Indonesia web to be inaccessible during the downtime.

\subsubsection{Final Network Testing}

In this final network testing the author applies HAProxy Server with two web servers available and one web backup server that has been clustered with HAProxy server on the Google Cloud Platform. The first test is to test the HAProxy server to see latency when you want to communicate or access a Virtual Private Server (VPS) in the Google Cloud Platform environment, for the results of the test can be seen in figure 9 .

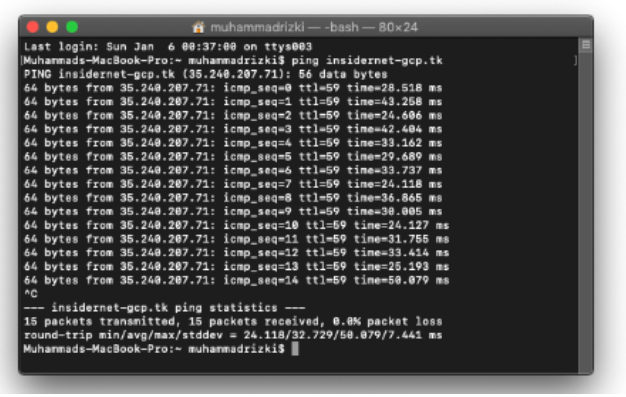

Figure 9. HAProxy VPS Ping test

Can be seen in Figure 9 the ping latency is only about $30 \mathrm{Ms}$ tested with the same internet network when testing the network running, this of course affects the access speed of the web server in serving requests from clients. The second test is testing whether the system load balance using the round robin method has been running after clustering configuration on the VPS HAProxy on the Google Cloud Platform. The test results can be seen in the picture below.

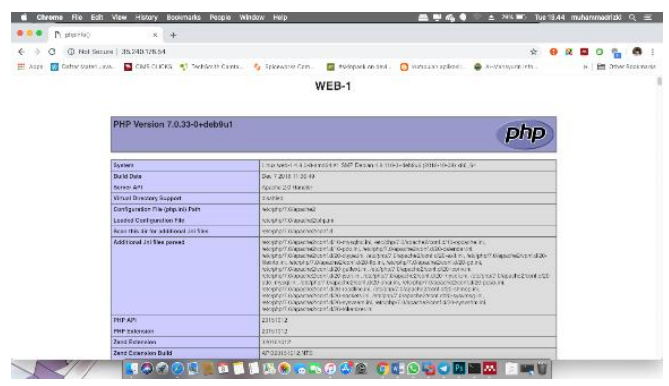

Figure 10. Testing Request to VPS HAProxy IP via Web Browser

In figure 10. Testing is done using the google chrome web browser to go to the VPS HAProxy public IP and display web data on the web-1 server. Then when the web browser requests to the same IP via a web browser, the result is a web browser on the client computer that displays web data on the web-2 server. For the results of testing after being refreshed and pointing to web-2, see Figure 11 . 


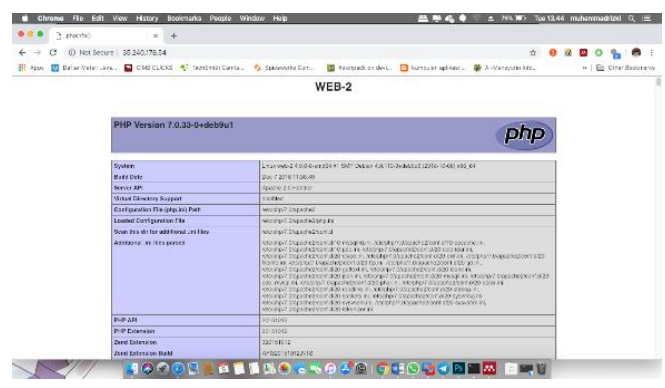

Figure 11. Request to VPS HAProxy IP via the second web browser (web-2)

Based on the results of network testing that the authors propose with the network that is running, then for the comparison results can be seen in the comparison table Table 1.

Table 1.

Comparison of Performance of PT Lintas Data Indonesia's Web Server System

\begin{tabular}{|c|c|c|c|}
\hline No & Pengujian & Jaringan Berjalan & Jaringan Usulan \\
\hline 1 & Latency & $\geq 200 \mathrm{Ms}$ & $\geq 30 \mathrm{Ms}$ \\
\hline 2 & Availabiity & 7 Menit Down & - \\
\hline 3 & Backup Server & Tidak ada & $\begin{array}{l}1 \text { Server } \\
\text { Backup }\end{array}$ \\
\hline 4 & Load Balance & 1 Server Aktif & $\begin{array}{l}2 \text { Server } \\
\text { Aktif }\end{array}$ \\
\hline 5 & $\begin{array}{l}\text { Upgradeable } \\
\text { Server }\end{array}$ & Tidak Support & Support \\
\hline 6 & $\begin{array}{l}\text { Monitoring } \\
\text { System }\end{array}$ & Tidak ada & $\begin{array}{c}\text { HAProxy } \\
\text { Monitoring }\end{array}$ \\
\hline
\end{tabular}

\section{CONCLUSION AND SUGGESTION}

After analyzing and designing Load Balance by using the HAProxy server server as described in the previous chapter, there are some conclusions as follows:

Through a temporary evaluation of the results of experiments conducted using a ping test to test the lantency between HostGator and Google Cloud Platform, there were significant differences in the results of test latency on the Google Cloud Platform. The advantages of Google Cloud Platform are servers that are rented for web servers in the form of Virtual Private Servers (VPS) so that they are easy to maintain and if you want to upgrade services. The addition of three web servers in the cluster with HAProxy server makes PT Lintas Data Indonesia's web server service more reliable in handling requests, load balances with round robin methods and fail over web servers and with HAProxy it is proven that it can increase up to $150 \%$ in handling latency issues previously it was around $30 \mathrm{Ms}$. Security in the Google Cloud Platform environment is easier to implement because it does not need to overspend in securing the VPS system in Google Cloud Compute Engine, because the cloud firewall rules feature of Google Cloud Platform is considered more than enough to secure virtual web server PT Lintas Data Indonesia's.

The suggestions that can be given in the development of computer networks in PT Lintas Data Indonesia to improve network performance or system capabilities in the future are as follows:

1. In the future, it is recommended to implement the proposed design thoroughly so that the performance of PT Lintas Data Indonesia's web server in serving requests from users or clients can increase.

2. Perform maintenance on the system that is running and pay more attention to the performance of the server that is now used and hosted on HostGator in order to find out the performance of PT Lintas Data Indonesia's web server has matched the expected results.

\section{ACKNOWLEDGMENT}

We would like to take this opportunity to thank all contributors of this journal. A special thanks to Dr. Mochamad Wahyudi, MM, M.Kom, M.Pd for his invaluable encouragement, guidance and support. Not forgetting also a big thanks to the team of the Journal SINKRON Politeknik Ganesha, Medan.

\section{REFERENCES}

Challita, Stéphanie et al. 2018. “A Precise Model for Google Cloud Platform To Cite This Version : HAL Id : Hal-01689659 A Precise Model for Google Cloud Platform."

Lumena, Dicky, Anton Anton, and Esron Rikardo Nainggolan. 2016. "Analisa Dan Perancangan Jaringan Private Cloud Computing Berbasis Web Eyeos." Jurnal Techno Nusa Mandiri 13(1): $1-8$. http://ejournal.nusamandiri.ac.id/ejurnal/index. php/techno/article/view/259/219.

Mengistu, Tessema et al. 2017. "A 'No Data Center' Solution to Cloud Computing." IEEE International Conference on Cloud Computing, CLOUD 2017-June(February 2018): 714-17.

Patwiyanto., Wahyuni, S., Prasetyo, S. A. 2018. Teknologi Layanan Jaringan - Kompotensi Keahlian Teknik Komputer Dan Jaringan. Yogyakarta: Andi.

Rosalia, Maya, Rendy Munadi, and Ratna Mayasari. 2016. "Implementasi High Availability Server 
Menggunakan Metode Load Balancing Dan Failover Pada Virtual Web Server Cluster." $e$ Proceeding of Engineering 3(3): 4496-4503.

Singh, Gurasis, and Kamalpreet Kaur. 2018. "An Improved Weighted Least Connection Scheduling Algorithm for Load Balancing in Web Cluster Systems." : 1950-55. 